\title{
Cobalt-Iron alloy nanoparticles impregnated partially graphitized carbon adsorbent from metallized bagasse for organic pollutants removal
}

\author{
Sai Rashmi Manipaddy, ${ }^{a}$ Akhila S, ${ }^{\text {a }}$ Velvita Duas, ${ }^{a, b^{\dagger}}$ Ashish Singh, ${ }^{c}$ Akshaya Kumar Samal, ${ }^{a}$ Rupesh S. \\ Devan, ${ }^{\mathrm{d}}$ and Manav Saxena*a

\begin{abstract}
Here, we report a highly efficient adsorbent obtained from the carbonization of metallized bagasse. The material is characterized using FESEM, HRTEM, PXRD, zeta-potential and VSM techniques. The material shows an impressive adsorbent property for anionic dyes, pharmaceutical (paracetamol) along with commercially used 'hair dye'. Further, $\mathrm{pH}$ triggered adsorption of Methylene orange (MO), Congo red (CR), Amido black (AB), and paracetamol were studied and results show an impressive adsorption capacity of $1102.9,1253.9,877.2,227.8 \mathrm{mg} / \mathrm{g}$ respectively. It is seen that under experimental conditions, adsorbent shows ultrafast adsorption kinetics where $\sim 96 \%$ AB dye gets adsorbed in just $5 \mathrm{~min}, 93 \%$ of $C R$ adsorption in $5 \mathrm{~min}$ and $\sim 89 \%$ of $\mathrm{MO}$ adsorption in $5 \mathrm{~min}$. Also, we could observe fast adsorption rate for commercially used 'hair dye' and paracetamol drug. Interestingly, in just $5 \mathrm{~min}, 95 \%$ of hair dye adsorption is seen and $~ 84 \%$ drug removal with maximum adsorption capacity of , recyclibility of the adsorbent demonstrates the practical benefits of the material for waste water remediation.
\end{abstract}

\section{Introduction}

Presently, water pollution has become most critical challenging issue among researchers, environmentalists and to the society. The surface water is contaminated by release of various industrial and domestic water contaminants such as synthetic dyes and pharmaceutical drugs. These dyes come out as contaminants in the effluents from textile, leather, paper, paint industries or personal hair coloring. ${ }^{1}$ On the other hand, the easy accesses to self-medication of pharmaceutical compounds around the globe have made the pharmaceuticals as one of the newly emerging pollutant directly discharged into the aquatic environment. ${ }^{2-3}$ The dyes and pharmaceutical waste presence in the water bodies is toxic, undesirable, causes exasperation to aquatic-lives, inhibit photo-synthesis process and thus the treatment of dye/ pharmaceutical wastewater has become a critical problem to be answered.

$\sim 90 \%$ of the commercial dyes are highly unwelcome due to their toxic/carcinogenic nature, and high LD $_{50}$ value $(2 \mathrm{~g} / \mathrm{kg}) .^{4-5}$ Azo dyes, the major organic pollutants from different industries, are potentially carcinogenic, stable and recalcitrant in nature. Azo dyes have azo bonds (-N=N-) in their chemical structure with functional groups such as $-\mathrm{OH}$ and $-\mathrm{SO}_{3} \mathrm{H}$. Thus, disposal of such dye contaminated wastewater possesses serious environmental and human health threats. 6-7 Congo Red (CR), Amido Black ( $A B)$ and Methyl Orange (MO) are the common

\footnotetext{
a. Centre for Nano and Material Sciences, Jain University, Bangalore, Karnataka562112, India.Email: s.manav@jainuniversity.ac.in; manavsaxena19@gmail.com b. Department of Chemistry, St. Aloysius College, Mangalore, Karnataka-575003, India.

c. Department of Chemistry, Indian Institute of Technology Kanpur, Kanpur, Uttar Pradesh-208016, India.

d. Department of Metallurgy Engineering and Materials Science, Indian Institute of Technology Indore, Indore, Madhya Pradesh-453552, India.

† These authors contributed equally.

Electronic Supplementary Information (ESI) available: [HRTEM of CFC-1, adsorption data of $C R, M O, A B$, hair dye and paracetamol over CFC-1, Kinetic data for adsorption study, control adsorbent (CFC-0, CC, CF) adsorption kinetic study]. See DOI: $10.1039 / x 0 \times x 00000 x$
}

anionic azo dyes of industrial applications. $C R$ and $A B$ shows carcinogenic and mutagenic properties ${ }^{8-10}$ and the acute exposure of $\mathrm{MO}$ can cause vomiting, increased heart rate, cyanosis, shock and tissue necrosis in humans. ${ }^{11}$

In addition, hair coloring is the common activity as a fashion status to enhance the hair appearance. The hair color is stable against the air, light, friction and chlorinated water. ${ }^{12}$ The direct discharge of the hair dye by the end-user without any treatment is a forewarning but a disregarded issue. Hair dye chemicals have been suggested as possible carcinogens or mutagens. ${ }^{13-15}$

Another serious worldwide pollution problem is caused due to the pharmaceutical products. Paracetamol ( $\mathrm{N}$-acetyl-paminophenol), under different trade name like Calpol, Panadol, Acet etc., is a popular drug used worldwide for humans and animals with analgesic and antipyretic properties used to treat fever and head/minor-aches. ${ }^{16}$ Paracetamol shows adverse effect such as hepatotoxicity, Stevens-Johnson syndrome and toxic epidermal necrolysis. 17-18 Even a low concentration of pharmaceuticals can lead to aquatic toxicity, genotoxicity and endocrine disruption and also can develop resistance in pathogenic microbes. ${ }^{19}$

Thus, we have selected azo dyes [Congo Red (CR), Amido Black (AB), Methyl Orange (MO)], GARNIeR ${ }^{\text {TM }}$ hair color and Paracetamol as a pharmaceutical waste for the present study.

Various compelling techniques have been proposed and implemented for the dyes and pharmaceutical waste removal such as biological treatment, nanofiltration, membrane separation, chemical flocculation, chemical oxidation, adsorption and electrochemical method, etc. 20 Amid all, adsorption is considered to be one of the leading techniques with an easy operation, high separation efficiencies, cost effective, and thus become the pivot of present water purification research.

Among different adsorbents, ${ }^{21}$ carbon-metal oxide-based magnetic composites show higher efficiency for the adsorption process due to its high porosity and surface area which touches to high adsorption capacity. In addition, due to magnetic 
property, it could be easily separated from reaction mixture. Among different metal oxide, iron ${ }^{22-26}$, manganese, ${ }^{7}$ zinc ${ }^{27}$ and nickel ${ }^{5,28}$ oxides are more explored as compared to the cobalt or cobalt-containing mixed metal oxides. Zhao et al. reported porous Fe( $\mathrm{OH})_{3} @$ cellulose hybrid fibers for effective removal of Congo Red with maximum adsorption capacity of $689.6 \mathrm{mg} \mathrm{g}^{-1}$. $29 \mathrm{Mou}$ et al. had reported hydrothermal synthesis of porous $\mathrm{Fe}_{3} \mathrm{O}_{4}$ magnetic nanoparticles based on dimethylacetamide (DMAc)/ethanolamine (ETA)/ azobis(isobutyronitrile) (AIBN) with maximum adsorption capacity of $46.7 \mathrm{mg}^{-g^{-1}}$ for methyl orange. ${ }^{24} \mathrm{Li}$ et al. had reported ionic liquid-based approach to synthesize cellulose-rich adsorbent aerogels from corn stalks. The prepared adsorbent shows absorption capacity of $549 \mathrm{mg}$ $\mathrm{g}^{-1}$ for Congo red. ${ }^{30}$ Mohanta et al. had reported synthesis of cobalt oxide nanoparticles (CONP) using a modified selfpropagator combustion method triggered by sucrose as the fuel. ${ }^{31}$ The CONP shows maximum adsorption capacity of $238.10 \mathrm{mg} \mathrm{g}^{-1}$ for malachite green. Hara et al. have reported synthesis and application of iron(III) oxyhydroxide monoliths for the adsorption of Congo red with maximum adsorption capacity of $467 \mathrm{mg} \mathrm{g}^{-1}$. ${ }^{32}$ Mateo del Rio et al. had reported Co particles embeddedMOF@Carbon hybrid magnetic adsorbent for Congo red. The Co-based material showed maximum adsorption capacity of $180 \mathrm{mg} \mathrm{g}^{-1}{ }^{33}$

Herein, we report the synthesis of cobalt-iron alloy impregnated partially graphitized layered carbon derived from cobalt-iron pre-treated bagasse via carbonization method. The synthesized material shows higher dye active surface area, faster adsorption kinetics and higher adsorption capacity towards industrial anionic dyes ( $C R, M O, A B)$, hair color and paracetamol, an analgesic and antipyretic drug. The higher adsorption capacity, reusability of the adsorbent material made them suitable for real-time application.

\section{Experimental details}

\subsection{Adsorbent synthesis}

Bagasse was collected, cleaned and powdered as per our earlier report. $3420 \mathrm{ml}$ of equimolar $(0.25 \mathrm{M}) \mathrm{Fe}\left(\mathrm{NO}_{3}\right)_{3} \cdot 9 \mathrm{H}_{2} \mathrm{O}$ and $\mathrm{Co}\left(\mathrm{NO}_{3}\right)_{3} \cdot 6 \mathrm{H}_{2} \mathrm{O}$ aq. solution (S.D. Fine Chemicals, India) each were mixed in a $250 \mathrm{~mL}$ beaker and kept for 30 min to attain an equilibrium. $5 \mathrm{~g}$ powdered bagasse was soaked in a mixed solution of $\mathrm{Fe}^{3+}$ and $\mathrm{Co}^{3+}$ ions and stirred well at $250 \mathrm{rpm}$ for $3 \mathrm{~h}$ and left undisturbed for $24 \mathrm{~h}$ at $30{ }^{\circ} \mathrm{C}$. The soaked bagasse was dried at $60^{\circ} \mathrm{C}$ for $12 \mathrm{~h}$ in a hot air oven. The dried Co-Fe soaked bagasse was kept in a quartz tube furnace for carbonization. The target temperature $\left(900^{\circ} \mathrm{C}\right)$ for carbonization was achieved at a heating rate of $10{ }^{\circ} \mathrm{C} \cdot \mathrm{min}^{-1}$ under $\mathrm{N}_{2}$ atmosphere. The furnace was maintained at $900^{\circ} \mathrm{C}$ for $1 \mathrm{~h}$ and then allowed to cool down to room temperature under $\mathrm{N}_{2}$ flow. The obtained composite is named as CFC-1 in the manuscript. Also, control samples only with $\mathrm{Fe}^{3+}, \mathrm{Co}^{3+}$ ions and without any metal ions; were also synthesized under same reaction conditions for comparative studies. Controlled samples are named as CF (with $\mathrm{Fe}^{3+}$ ), CC (with $\mathrm{Co}^{3+}$ ), CFC-0 (no metal ions) respectively further in the manuscript.

\subsection{Characterization}

Surface morphology of the samples was studied using Thermo Scientific ${ }^{\mathrm{TM}}$ Talos $^{\mathrm{TM}}$ F200S High-Resolution Transmission Electron Microscopy (HRTEM) working at 200kV. Powder X-ray diffraction pattern (PXRD) (Rigaku X-ray diffraction ultima-IV, Japan) was recorded over a range of $5^{\circ}$ to $70^{\circ}$ with a scan speed of $1^{\circ} \mathrm{min}^{-1}$ using $\mathrm{Cu}-\mathrm{K}_{\alpha}$ radiation. Zeta potential was done in aqueous solution using Omega Cuvete $Z$ with Litesizer 500 (Anton Paar). The room temperature magnetic hysteresis (M-H) loops were recorded using a vibrating sample magnetometry (VSM) system (ADE, EV7 model) with a maximum field of 18000 $\mathrm{O}_{\mathrm{e}}$. Based on the Barrett-Joyner-Halenda (BJH) model, pore size distribution plots were recorded from the desorption isotherms. Prior to the measurement, the samples were degassed at $150^{\circ} \mathrm{C}$ under vacuum for $12 \mathrm{~h}$. UV-Vis absorption studies were carried out with Perkin Lambda 365 spectrophotometer using $10 \mathrm{~mm}$ quartz cuvette.

\subsection{Dye adsorption study}

All the adsorption experiments were carried out at STP. $50 \mathrm{ppm}$ of Congo red (CR), Methyl Orange (MO), and Amido Black (AB) dye solutions were used as adsorbates and CFC-0, CF, CC and CFC-1 materials were used as adsorbents. In order to find the optimal $\mathrm{pH}$ for dye adsorption study, the dye solutions were adjusted to $\mathrm{pH} 2-10$ using $0.1 \mathrm{M} \mathrm{HCl}$ or $0.1 \mathrm{M} \mathrm{NaOH}$ solution as required. For the adsorption study, the optimized quantity of adsorbent ( $6 \mathrm{mg}$, see 3.2.2) were added to $50 \mathrm{ppm}$ dye solution at an optimal $\mathrm{pH}$ and sonicated for $2 \mathrm{~min}$. The solution was then stirred at $250 \mathrm{rpm}$ for a particular time. Meanwhile, as a time dependent experiment, $2 \mathrm{ml}$ of the dye solution was removed at different time intervals and the adsorbent (CF/CC/CFC-1) was separated using an external magnet. However, as CFC-0 is nonmagnetic in nature, the solution was centrifuged up to 5000 $\mathrm{rpm}$ for $15 \mathrm{~min}$. The clear solution was taken in a $10 \mathrm{~mm}$ quartz cuvette to measure the amount of left-over dye using UV-Vis absorption spectrophotometer at $\lambda_{\text {abs }} 618,463$ and $496 \mathrm{~nm}$ for $A B, M O$, and $C R$ respectively. Equation 1 and 2 were used to calculate percentage dye removal and adsorption efficiency respectively.

$$
\begin{aligned}
& \text { Dye removal }(\%)=\frac{C_{o}-C_{t}}{C_{o}} \times 100 \\
& q_{e}=\frac{\left(C_{o}-C_{e}\right) V}{W}
\end{aligned}
$$

$\mathrm{C}_{\mathrm{o}}$ and $\mathrm{C}_{\mathrm{t}}(\mathrm{mg} / \mathrm{L})$ are the concentration of the dye solution at initial $(t=0)$ and time ' $t$ '. $C_{e}$ represents the equilibrium concentration of dye solution; $V$ is the volume (L) of the aqueous dye solution and $\mathrm{W}(\mathrm{g})$ is the weight of the adsorbent used. The kinetic study was carried out and analyzed using Pseudo-first order and Pseudo-second order model fitting using respective mathematical equations are given as equation S1 and $\mathrm{S} 2$ in $\mathrm{SI}$, respectively. Additionally, the isotherm study was carried out for $A B, M O$ and $C R$ using $100-600$ ppm of dye solution in order to calculate the maximum adsorption capacity $\left(q_{m}\right)$ of the adsorbent. Langmuir isotherm and Freundlich 
isotherm models were used to study the adsorption behavior of CFC-1 and using respective mathematical equations (equation S3 and S4 of SI).

\subsection{Paracetamol adsorption kinetic study}

$6 \mathrm{mg}$ CFC-1 was added to the $15 \mathrm{ml}$ of $10 \mathrm{ppm}$ of paracetamol solution at optimized $\mathrm{pH}$ as method described in section 2.3. The mixture was sonicated for $2 \mathrm{~min}$ and stirred at $250 \mathrm{rpm}$. Kinetic study was performed by collecting the drug solution at 5 min interval and measured absorbance at $243 \mathrm{~nm}$ to calculate its concentration as mentioned in the adsorption study (section 2.3). Isotherm study was also carried out using 50-250 ppm of drug solution. Further, maximum adsorption capacity of CFC-1 was calculated as per the equations using different isotherm models (equation S3 and S4 of SI).

\section{Result and Discussions}

\subsection{Adsorbent characterization}

In an aqueous solution of $\mathrm{Co}^{3+}$ and $\mathrm{Fe}^{3+}$ ions, the $\mathrm{Co}^{3+}$ and $\mathrm{Fe}^{3+}$ ions are homogenously mixed due to the similar ionic radius. The coordinating capability of oxygen of $-\mathrm{OCH}_{3} /-\mathrm{C}=\mathrm{O} / \mathrm{Ph}-\mathrm{OH}$ functional groups from sugar and lignin moieties, allows homogenous distribution of $\mathrm{Co}^{3+}-\mathrm{Fe}^{3+}$ throughout the bagasse with the different oxygen functional groups which further lead to the formation of homogeneous distribution of nanoparticles upon carbonization. ${ }^{34-36}$

The FESEM analysis was performed for the surface morphology characterization of CFC-1. Figure $2(a, b)$ are the low and high magnification images of CFC-1 respectively. The FESEM confirms the homogeneously embedded nanoparticles in the layered carbon whereas the control sample CFC-0 has only layered carbon as reported in our previous study. ${ }^{36}$ The crystallographic structure of as prepared CFC- 1 is analyzed by PXRD and displays in Figure 2c. The intense peaks at $2 \theta=45.1^{\circ}$ and $65.6^{\circ}$ corresponds to the (011) and (020) plane of bcc-CoFe alloy (space group Im $\overline{3} \mathrm{~m}$, a: $2.849 \AA$ in CFC-1 (reference code: 96-152-4168) which is also in consistent with previous literatures. ${ }^{37-38}$ PXRD of CFC-1 shows sharp peaks suggesting the crystalline nature/crystallites in the material. The small peak at $2 \theta=35.6^{\circ}$ in the pattern is corresponding to the presence of cobalt ferrite. ${ }^{38}$ The small peak at $2 \theta=26.3^{\circ}$ and $43.9^{\circ}$ corresponds to the (002) and (100) respectively for the graphitic carbon formed with an interlayer spacing of $\sim 3.4 \pm 0.2 \AA$.
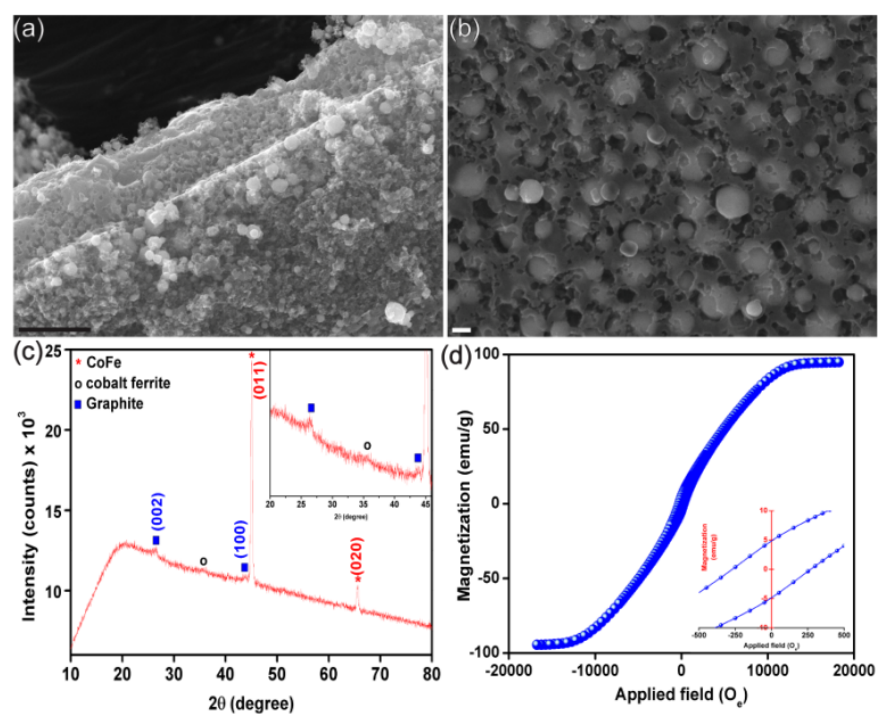

Figure 2: (a, b) FESEM image of CFC-1, scale bar: (a) $1 \mu \mathrm{m}$ (b) $100 \mathrm{~nm}$. (c) PXRD of CFC-1, (d) Magnetic hysteresis curve of CFC-1. The inset is a magnified view of the magnetization versus field curves.

The formation of graphitic structure is interesting and could be explained on the basis of role of cobalt and iron. Carbon has temperature dependent solubility in the $\mathrm{Co}$ and $\mathrm{Fe} \sim 0.6-0.7$ at\% at $900{ }^{\circ} \mathrm{C}$. Upon heating to $900{ }^{\circ} \mathrm{C}$, Co and Fe tend to form a stable metallic alloy CoFe due to the high miscibility over the vast temperature range as supported by the Co-Fe phase diagram with simultaneous following carbon reduction of their respective oxides to give CoFe alloy. During the alloying and carbon reduction reaction, the carbon diffuses into the alloy particles. The temperature dependency of carbon solubility leads to the carbon segregation from the bulk toward surface during cooling and catalyzed the growth of graphitic layers. However due to the very low carbon solubility in Co or Fe as compared to high mutual solubility of Co into the Fe and viceversa, the carbon precipitate out as defected graphitized layers with similar mechanistic way as reported. ${ }^{36,39}$ In addition, the peaks that could be assigned to unreduced Fe and Co precursor or non-alloyed $\mathrm{Fe} / \mathrm{Co}$ is not observed.

The successful magnetic separation of the adsorbent by applying an external magnetic field from the reaction mixture is a very expedient and potent method to recover adsorbent and essential for the real time application. The magnetic property of CFC-1 is investigated by VSM at $300 \mathrm{~K}$. Figure $2 \mathrm{~d}$ presents the magnetization hysteresis curve of CFC-1. The hysteresis curve of CFC-1 showed that the saturation magnetization $\left(M_{s}\right)$ is 94.7 $\mathrm{emu}^{-1}$ at $300 \mathrm{~K}$ which is much higher than the $0.01 \mathrm{emu} \mathrm{g}^{-1}$ of control sample reported earlier. ${ }^{34}$ It is worth noted that such simple synthesis of carbon supported CoFe alloy show saturation magnetization much higher than the reported values of $17.78 \mathrm{emu} / \mathrm{g}$ for cobalt oxide $3171.3 \mathrm{emu} / \mathrm{g}$ for $\mathrm{Fe}_{3} \mathrm{O}_{4}{ }^{23} 59.12$ $\mathrm{emu} / \mathrm{g}$ for $\mathrm{Fe}_{3} \mathrm{O}_{4}{ }^{24} 39.1 \mathrm{emu} / \mathrm{g}$ for $\mathrm{CoFe}_{2} \mathrm{O}_{4}{ }^{40} 48.5 \mathrm{emu} / \mathrm{g}$ for cementite/iron porous carbon ${ }^{41}$ and $6.1 \mathrm{emu} / \mathrm{g}$ for $\mathrm{cl}-\mathrm{CS}$ $\mathrm{p}(\mathrm{MA}) / \mathrm{GO}-\mathrm{Fe}_{3} \mathrm{O}_{4}$. ${ }^{26} 27.49 \mathrm{emu} / \mathrm{g}$ for $\mathrm{Fe}_{3} \mathrm{C} / \mathrm{Fe} / \mathrm{C}$ magnetic hierarchical porous carbon ${ }^{42}$ and 59.20 for $\mathrm{CoFe}_{2} \mathrm{O}_{4} / \mathrm{rGO}{ }^{43}$ which is enough to separate adsorbent from the reaction mixture. The values of coercivity $\left(H_{c}\right)$, remanence $\left(M_{r}\right)$, and 
squareness ratio (ratio between $\mathrm{M}_{\mathrm{r}}$ and $\mathrm{M}_{\mathrm{s}}$ ) are $273 \mathrm{O}_{\mathrm{e}}, 4.9 \mathrm{emu}$ $\mathrm{g}^{-1}$ and $5.0 \%$ respectively. The low squareness ratio suggested the material is in super-paramagnetic state at room temperature. ${ }^{34,44-47}$

The TEM characterization was used to study detailed surface morphology of the CFC- 0 and CFC- 1 material. The HRTEM of the control sample (CFC-0) suggested the layered structure (Figure 3a). The absence of the graphitized layers suggested amorphous nature of the CFC- 0 which is further supported by diffused ring SAED pattern (Figure $3 \mathrm{~b}$ ) and broad peaks in PXRD as reported earlier. ${ }^{34}$ CFC- 1 shows the polydisperse CoFe alloy particles of approx. 20-120 $\mathrm{nm}$ in size dispersed throughout the layered carbon structure (Figure $3 c$ ). The carbon layer is partially graphitized (interlayer spacing of 3.2-4.0 $\AA$, Figure S1) which is further corroborated by PXRD, due to the partial solubility of carbon in $\mathrm{Co} / \mathrm{Fe}$ or CoFe at high temperature and dissolution from bulk while cooling as explained above. The CoFe alloy nanoparticles are well embedded in the carbon layer structure (Figure $3 \mathrm{c}$-e). HRTEM image of CoFe alloy nanoparticle shows the d-spacing of $2.0( \pm 0.1) \AA$ (inset of Figure 3e) corresponds to the (011) crystal plane for CoFe alloy bcc structure, which is further supported by PXRD (Figure 2c). ${ }^{48}$ Selected area electron diffraction (SAED) pattern of CFC-1 shows characteristic diffraction spots for different planes of graphite and CoFe alloy and thus confirms the formation of CoFe@C composite (Figure 3f).

The formation of CoFe alloy on carbon supported layer is confirmed in details by high-angle annular dark-field (HAADF) elemental mapping (Figure 4). The HAADF image of CoFe@C confirms the homogeneously distributed CoFe alloy nanoparticles are embedded in carbon layer matrix (Figure 4a). $\mathrm{Co}$ and Fe elemental mapping, Figure $4 \mathrm{~b}$ and $4 \mathrm{c}$ respectively confirms the formation of CoFe alloy nanoparticles which is in accordance of PXRD, HRTEM and SAED analysis. The lower contrast of $O$ mapping (Figure $4 d$ ) suggests a very small amount of oxide present which is further supported by small peak at $2 \theta$ $=35.6^{\circ}$ for cobalt ferrite in PXRD and adsorbed atmospheric oxygen on the sample. The low amount of oxygen is also supported by EDAX of CFC-1 (Figure 4h). N and C elemental mapping confirms that carbon layer has low amount of hetero atom doping (Figure $4 \mathrm{e}, \mathrm{f}$ ). Figure $4 \mathrm{~g}$ is an overlap image of HAADF and Co, Fe, O, C and $\mathrm{N}$ elemental mapping confirms the presence of CoFe alloy well embedded in the carbon layer.
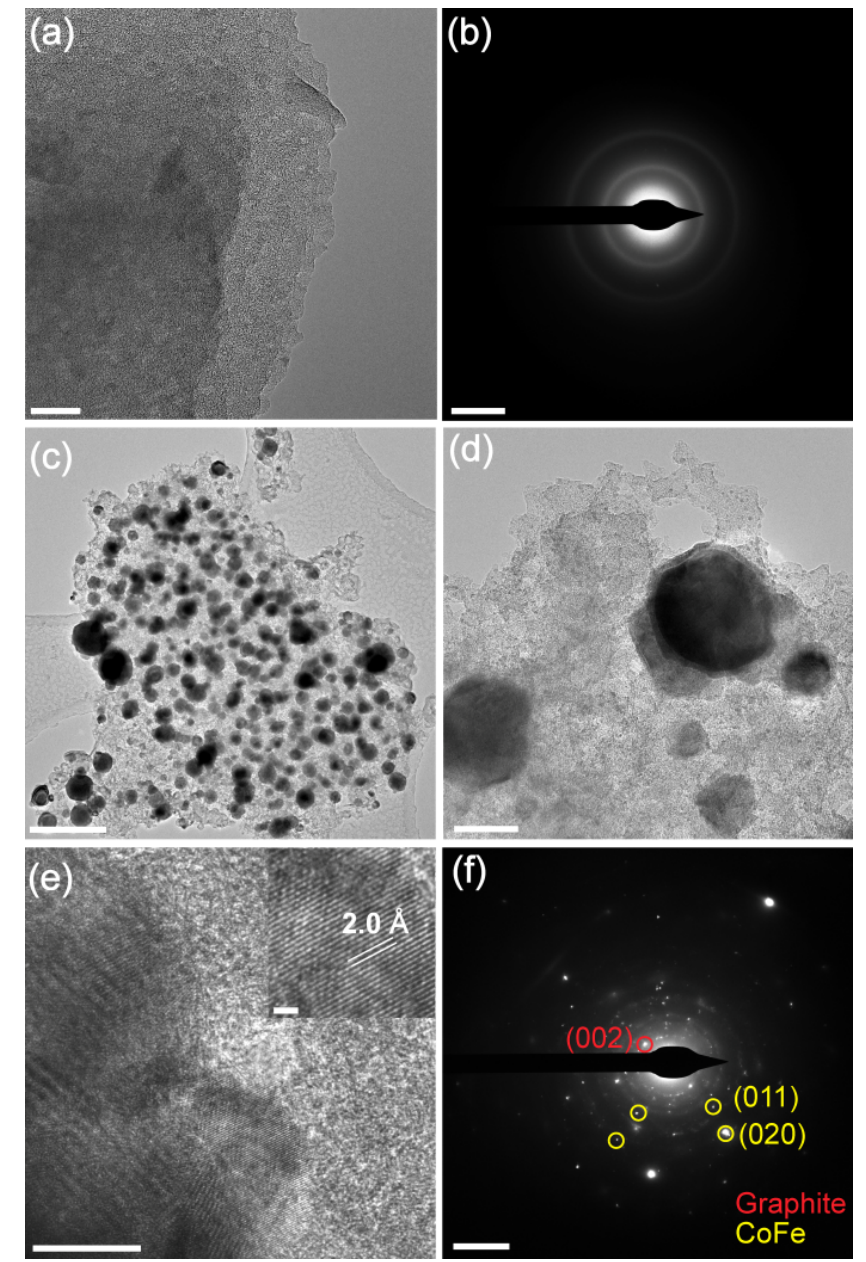

Figure 3: (a) HRTEM image of CFC-0, (b) SAED pattern of CFC-0 (c-e) HRTEM images of CFC-1 (f) SAED pattern of CFC-1. Scale bar: (a) $50 \mathrm{~nm}$, (b) $51 / \mathrm{nm}$, (c) $500 \mathrm{~nm}$, (d) $50 \mathrm{~nm}$, (e) $10 \mathrm{~nm}$, inset: $1 \mathrm{~nm}$ (f) $51 / \mathrm{nm}$.

\subsection{Adsorption study}

\subsubsection{Effect of $\mathrm{pH}$}

$\mathrm{pH}$ study is carried out by maintaining the $\mathrm{pH}$ of the solution. The anionic dyes show higher adsorption over CFC-1 at lower $\mathrm{pH}$. Maximum adsorption of $\mathrm{CR}$ dye was $97.4 \%$ at $\mathrm{pH}=3$ which decreased at $\mathrm{pH}=10$ to $89.7 \%$ (figure $\mathrm{S} 2 \mathrm{a}$ ). $\mathrm{MO}$ dye, shows maximum adsorption of $97.5 \%$ over CFC-1 at $\mathrm{pH} 3$ while it decreases to $69.9 \%$ at $\mathrm{pH} 10$ (Figure S3a). Similarly, AB dye $98.6 \%$ of adsorption at $\mathrm{pH}=3$ (figure $\mathrm{S} 4 \mathrm{a}$ ) and $60.7 \%$ adsorption at $\mathrm{pH}=10$. Interestingly, we also found that even the paracetamol drug and the hair dye showed the maximum adsorption at $\mathrm{pH}=3$. Figure $\mathrm{S} 5 \mathrm{a}$ and $\mathrm{S} 6 \mathrm{a}$ show the $72 \%$ of hair dye and $95.2 \%$ adsorption for paracetamol respectively over CFC- 1 at $\mathrm{pH} 3$.

To explore the higher adsorption of anionic dyes at lower $\mathrm{pH}$ as compared to the higher, we had performed the surface charge analysis of the CFC- 1 adsorbent by the zeta potential measurements in a wide $\mathrm{pH}$ range $(\mathrm{pH} 3-10)$. The mechanism of the dye adsorption could be expressed based on the $\mathrm{pH}$ of zeropoint charge $\left(\mathrm{pH}_{2 \mathrm{pc}}\right)$ of an adsorbent (figure $5 \mathrm{a}$ ). At the $\mathrm{pH} 3,5$, $7,8,10$, the CFC-1 materials surface shows charges like +29.4 , $11.3,-21.9,-22.1$, and $-27.2 \mathrm{mV}$ respectively. As the surface of 
adsorbent bear positive charge at $\mathrm{pH}=3(+29.4)$ and dye surface possess negative groups, the adsorption of anionic dyes $M O, C R$, $A B$ and paracetamol is higher at $\mathrm{pH}=3$. Also due to high negative charge at $\mathrm{pH}=10(-27.2)$, we could observe the least adsorption of anionic dyes onto CFC-1 due to electrostatic repulsion. The $\mathrm{pH}_{\mathrm{zpc}}$ is found to be 4.4 (figure $5 \mathrm{a}$ ), where below this $\mathrm{pH}$, the adsorbent shows positive charge and above this $\mathrm{pH}$, adsorbent shows negative charges. For eg. $\mathrm{MO}$ dye, electrostatic attraction between $\mathrm{SO}_{3}{ }^{-}$groups and protonated sites on CFC- 1 takes place and the adsorption is favorable. In the present study, the paracetamol drug, the adsorption is favorable due to the electrostatic attraction between hydroxyl group present on the drug molecule and protonated sites on CFC-1 composite at $\mathrm{pH}=3 .{ }^{49}$ However, we can see adsorption is at basic conditions for paracetamol, which could be from $\pi-\pi$ interactions between benzene ring of carbon and the drug. Thus, electrostatic interaction of positively charged surface of CFC-1 and negatively charged dyes and drug molecules are responsible for the higher adsorption at $\mathrm{pH}=3$ along with the $\pi-\pi$ interactions.

\subsubsection{Dosage study}

The optimization of the amount of adsorbent is a key step for the dye adsorption study. Initially, the adsorption of MO dye was carried out by taking 2, 4, $6 \mathrm{mg}$ of the adsorbent for $15 \mathrm{ml}$ of $50 \mathrm{ppm}$ dye solution, described as dosage study at optimized $\mathrm{pH}$ (figure 5b). It is noted that $6 \mathrm{mg}$ of an adsorbent could adsorb $99.5 \%$ of $\mathrm{MO}$ dye, in $30 \mathrm{~min}$. As the amount of adsorbent increases, the percentage of adsorption also increases, which is due to the availability of higher adsorption sites on the surface of CFC-1 material. Hence, $6 \mathrm{mg}$ adsorbent was chosen and kept same for all other dyes further in the manuscript, in order to nullify the mass effect.
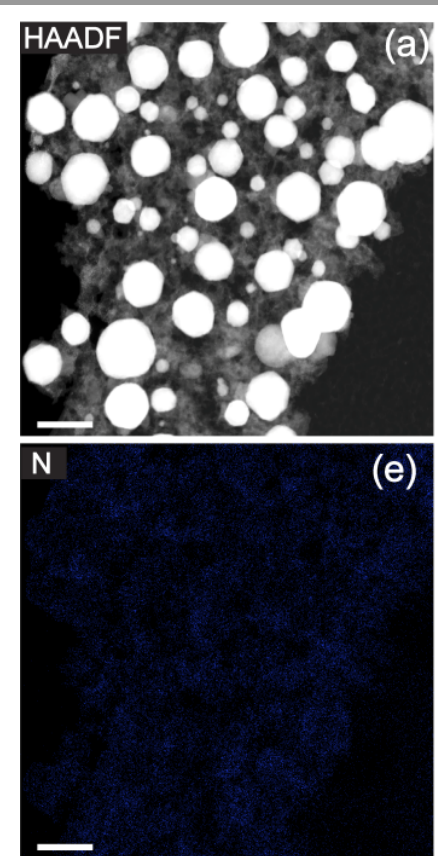
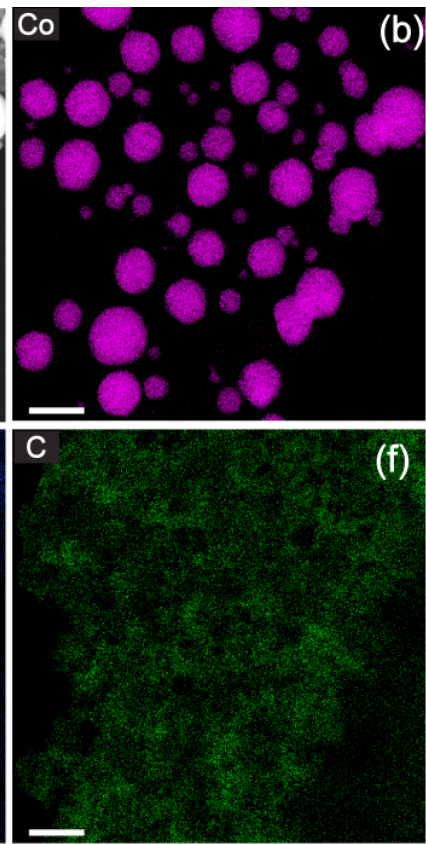
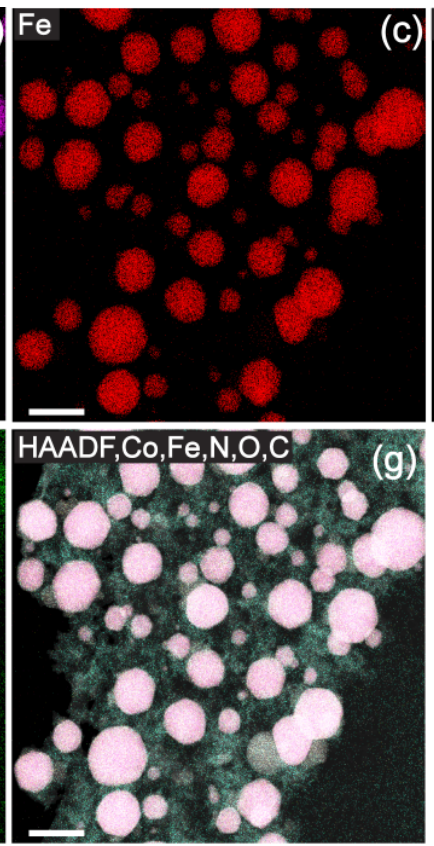
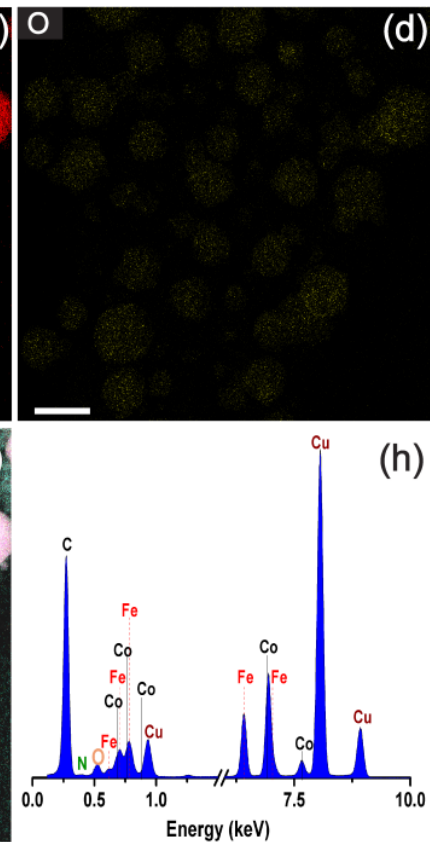

Figure 4: (a) HAADF image of CoFe-1. Elemental map of (b) Co, (c) Fe, (d) O, (e) N, (f) C (g) Overlap image of a-f. Scale bar: (a-g) $200 \mathrm{~nm}$ (h) EDAX of CoFe-1.
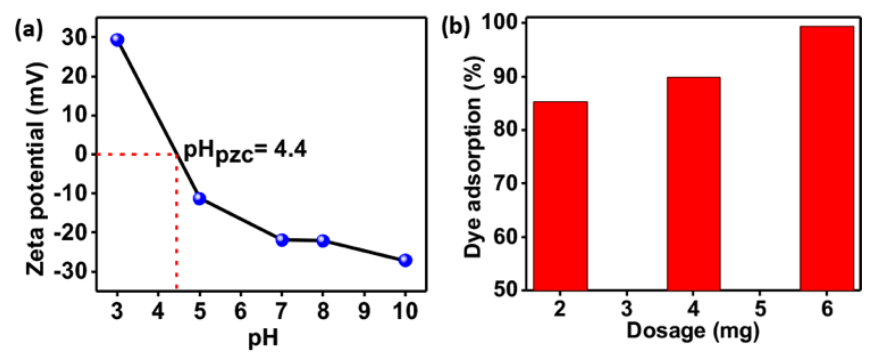

Figure 5: (a) effect of zero-point charge, (b) dosage study using $\mathrm{CFC}-1, \mathrm{pH}=3$, error \pm 2 $2.7 \% 50$ ppm MO dye

\subsubsection{Kinetic study}

\section{Congo Red adsorption:}

In order to describe the kinetic study, figure 6a shows the percentage removal of $\mathrm{CR}$ dye at $\mathrm{pH}=3$ using $\mathrm{CFC}-1$ composite at different time intervals. Percentage dye removal at different time intervals is depicted in figure $6 a$, where $93.1 \%$ of the dye gets adsorbed onto CFC-1 in just 5 min of time which is much higher than the control samples CFC-0 (31.9\%), CF (16.1\%) and CC (27.1\%) under similar reaction condition in $5 \mathrm{~min}$ (Figure S7). In addition, CR adsorption on CFC-1 are higher than recent reported values $75 \%$ in 6 min $^{22} \sim 50 \%$ in 5 min ${ }^{25} 85 \%$ in $15 \mathrm{~min}$ 8. The inset of figure 6 a shows that change in color of $C R$ dye from $\mathrm{pH}=7$ to $\mathrm{pH}=3$, which arises due to the structural change in $\mathrm{CR}$ at $\mathrm{pH}=3 .{ }^{27,50-52}$ After $5 \mathrm{~min}, \mathrm{CFC}-1$ shows adsorption capacity of $\mathrm{q}_{5 \min }=116.4 \mathrm{mg} / \mathrm{g}$ for CR dye (Figure S2c). In order to describe whether the kinetic model fits pseudo-first order or pseudosecond order model, the plots of $\ln \left(q_{\mathrm{e}}-\mathrm{q}_{\mathrm{t}}\right) \mathrm{vs} t$ and the plots of $t / q_{t} v s t$ were plotted. The kinetic experiment revealed that the CR dye adsorption follows pseudo-second order with $\mathrm{R}^{2}: 0.999$ (figure $6 \mathrm{~b}$, table $\mathrm{S} 1$ ), whereas $\mathrm{R}^{2}$ value for pseudo-first order kinetics is 0.638 (figure S2d). 


\section{Methyl Orange adsorption:}

Figure $6 \mathrm{~d}$ shows the percentage removal of dye at $\mathrm{pH}=3$ using CFC-1 composite at different time intervals. It is seen that, $89.1 \%$ of $\mathrm{MO}$ gets adsorbed in $5 \mathrm{~min}$ and $97.2 \%$ removal in 30 min which is comparable and higher than the CFC-0 (4.4\%), CF (25.2\%) and CC (15.0\%) (Figure S8 SI) and with the reported literatures. The adsorption capacity increases with increase in time and reaches to $q_{30 \min }=121.6 \mathrm{mg} / \mathrm{g}$ (Figure $\mathrm{S3c}$ ). The fitting of the $\ln \left(q_{e}-q_{t}\right)$ vs $t$ and $t / q_{t}$ vs $t$ plots were performed to elucidate the kinetic order of the adsorption process (figure S3d and 6 e respectively). For pseudo-second order kinetics, the correlation coefficient, $\mathrm{R}^{2}$ is calculated to be 0.999 , higher that pseudo-first order model (Figure S3d). Hence the adsorption of MO dye over CFC-1 adsorbent agrees to follow pseudo-second order, a chemisorption process.

\section{Amido Black adsorption}

Figure $6 \mathrm{~g}$ outlines the percentage adsorption of $A B$ dye at different intervals of time carried out with CFC- 1 composite, at $\mathrm{pH}=3$. Amido black adsorption is faster than $\mathrm{MO}$. According to figure $6 \mathrm{~g}$, in the $1^{\text {st }}$ min of adsorption process, $68.5 \%$ of $A B$ dye is removed and $95.8 \%$ of the dye removal is observed in just $5^{\text {th }}$ min. Moreover, the adsorption rate is 4-11 times faster as compared with the control sample CFC-0 (8.8\%), CF (25.2\%) and CC (18.9\%) (Figure S9). This ultrafast dye adsorption process also bears high adsorption capacity of $\mathrm{q}_{5 \mathrm{~min}}=120.0 \mathrm{mg} / \mathrm{g}$ as seen in figure S4c. The plots of pseudo-first order and pseudo-second order (figure S4d and $6 \mathrm{~h}$ respectively) reveals that the adsorption follows Pseudo-second order with $\mathrm{R}^{2}: 0.988$, which is higher to that of pseudo-first order whose correlation factor, $\mathrm{R}^{2}: 0.946$ (Table S1). Thus, the kinetics of $A B$ adsorption follows chemisorption process, which also supports Langmuir isotherm.

\section{Isotherm study}

To investigate the maximum adsorption capacity $\left(q_{m}\right)$ of the adsorbent, isotherm studies have been carried out using different concentrations of the adsorbate CFC-1. Figure $6 c, 6 f$ and $6 i$ reveals the Langmuir model of $C R, M O$ and $A B$ adsorption respectively and figure $\mathrm{S} 2 \mathrm{e}, \mathrm{S} 3 \mathrm{e}$ and $\mathrm{S} 4 \mathrm{e}$ describes the Freundlich adsorption model of $\mathrm{CR}, \mathrm{MO}$ and $\mathrm{AB}$ respectively. It is known that in Langmuir isotherm, the adsorbate molecules cannot interact each other but gets confined onto the surface of the adsorbent in a monolayer, which is also called as homogenous adsorption whereas, Freundlich model is based on the multilayer adsorption of adsorbate molecules, also called as heterogenous adsorption. ${ }^{53}$ It is found that the $\mathrm{R}^{2}$ value for $\mathrm{MO}$ dye is 0.986 for Langmuir model and 0.729 for Freundlich model, which clearly shows that the adsorption follows Langmuir isotherm for $\mathrm{MO}$ dye. Further the $\mathrm{R}^{2}$ value for $\mathrm{CR}$ is 0.996 for Langmuir model and 0.861 for Freundlich model. For $A B$, Langmuir and Freundlich isotherm model shows $R^{2}$ value of 0.931 and 0.887 respectively. The different factors related to isotherm models are tabulated in table S1. For $M O, C R$ and $A B$ dye, the $q_{m}$ value is found to be $1103.0 \mathrm{mg} / \mathrm{g}, 1254.0$ and 877.2 $\mathrm{mg} / \mathrm{g}$ respectively. These values are compared with recent reports and tabulated in table S2. Hence, we could conclude that CFC-1 bears very high maximum adsorption capacity for $\mathrm{MO}, \mathrm{CR}$ and $\mathrm{AB}$ dye by following Langmuir isotherm model, a homogenous monolayer adsorption.

\section{Removal of hair dye}

Hair coloring is very common and simple to use these days without any expertise. After wash, the hair color gets drained without any pretreatment. Due to the high stability of these hair dyes at environmental conditions, it is necessary to take a serious action towards the treatment of the waste hair colors, which could otherwise lead to a severe threat to water bodies and aquatic life. We have chosen GARNIeR color naturals (3.16 burgundy), a product of L'Oréal India Pvt. Ltd for this work. The hair dye was used as per the instructions given in leaf. In order to study the adsorption, first effect of $\mathrm{pH}$ on adsorption of dye over CFC-1 was studied at different $\mathrm{pH}$ ranges ( $\mathrm{pH}$ 3-10) using $0.1 \mathrm{M} \mathrm{HCl}$ or $0.1 \mathrm{M} \mathrm{NaOH}$. At $\mathrm{pH}=3$, the maximum adsorption could be seen to be $72.0 \%$ and at $\mathrm{pH}=10,16.6 \%$ adsorption was seen in 5 min (figure S5a). Further the kinetic study was carried out at $\mathrm{pH}=3$ due to maximum adsorption by CFC- 1 and the percentage adsorption with time is depicted in figure 7a. The inset shows the hair dye at $\mathrm{pH}=9$ (as obtained), further adjusted at $\mathrm{pH}=3$ and after adsorption. As seen in figure $\mathrm{S} 7 \mathrm{~b}$, at $\lambda_{\max }=500$ $\mathrm{nm}$, the absorbance value decreases with time and at $5^{\text {th }} \mathrm{min}$, $95.5 \%$ dye adsorption with an efficiency of $29.8 \mathrm{mg} / \mathrm{g}$ could be achieved (figure 7c). Moreover, the kinetic study carried out follows pseudo-first order with higher value of $R^{2}$ being 0.995 (figure $7 \mathrm{~b}$ ) as compared to pseudo second order with $\mathrm{R}^{2}$ value of 0.894 . (figure $\mathrm{S} 5 \mathrm{c}$ ), a process of physisorption. Overall, it is seen that fast and high adsorption of hair wash waste could be achieved using CFC-1 composite and thus useful for practical application.

\section{Adsorption of paracetamol}

Paracetamol (4'-hydroxyacetanilide, N-acetyl-p-aminophenol) is a common analgesic and antipyretic drug. Easy access and self-medication have made the Paracetamol as one of the pollutants that are commonly discharged into the aquatic environment and could be detected easily in surface waters, wastewater, and drinking water throughout the world. The CFC1 was mixed with $10 \mathrm{ppm}$ solution of paracetamol (maintained at $\mathrm{pH} 3)$ in 1:2.5 (w/v) ratio. This solution was sonicated for $2 \mathrm{~min}$ and stirred vigorously at $250 \mathrm{rpm}$. At every $5 \mathrm{~min}$ intervals of time, $2 \mathrm{ml}$ solution was taken out and the CFC-1 is separated using an external magnet. Further, the absorbance is measured using UV-Vis spectrophotometer and the concentration of the drug solution is calculated. Figure $7 \mathrm{~d}$ shows the time dependent sorption study of paracetamol where $83.5 \%$ adsorption was seen in $5^{\text {th }} \mathrm{min}$ and $94.2 \%$ removal could be achieved in $60^{\text {th }}$ min. After the linear fitting of the plots $\ln \left(q_{e}-q_{t}\right)$ vs $t$ and the plots of $t / q_{t} v s t$, the results show that the adsorption of paracetamol follows pseudo-second order kinetic model (figure $7 e)$. Isotherm analysis was carried out with the concentration of paracetamol ranging from 50-250 ppm to calculate maximum adsorption capacity of CFC-1 for paracetamol. We found that the maximum adsorption capacity of CFC-1 towards paracetamol is $227.8 \mathrm{mg} / \mathrm{g}$ by following Langmuir adsorption 
model depicted in (figure 7f). Ruiz et al reported the half uptake in 59 min which is $88 \%$ slower than the present study. ${ }^{16}$ Laldo et al. reported maximum sorption of paracetamol to be 261.0 $\mathrm{mg} / \mathrm{g}$ using activated carbon with half uptake in $206 \mathrm{~min}$ which is $\sim 71 \%$ slower than present study. ${ }^{54}$ Lucas et al. reported $\mathrm{q}_{\mathrm{m}}$ value to be $356.2 \mathrm{mg} / \mathrm{g}$ using super activated carbon produced by $\mathrm{KOH}$ activation of biomass waste. ${ }^{49}$ These reports are comparable and quite higher, however, the kinetics for the adsorption is much slower as compared to our results and regeneration of adsorbent is difficult as earlier reported adsorbent were non-magnetic in nature.
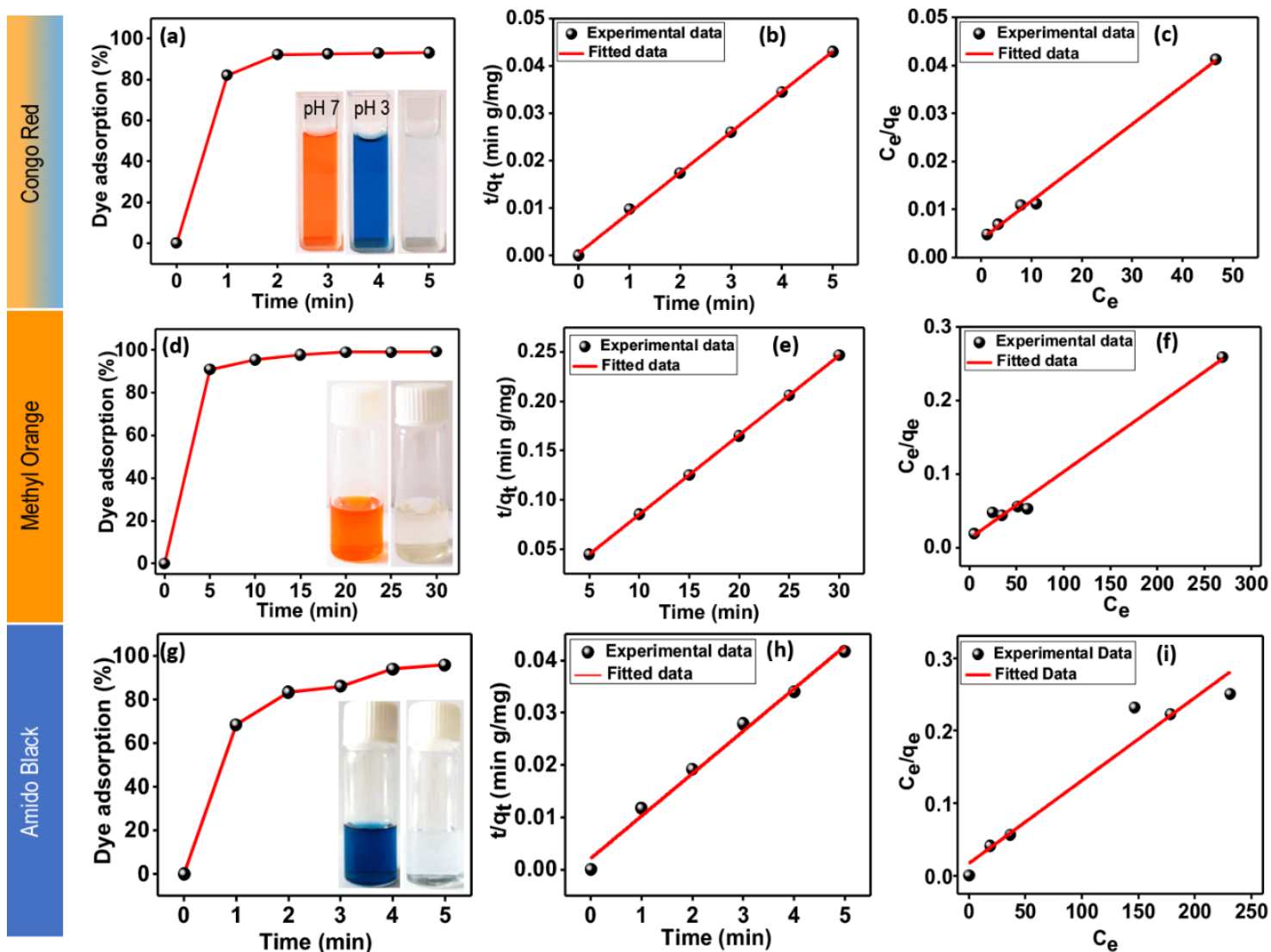

Figure 6: (a) CR dye removal efficiency with time (inset: optical image of $\mathrm{CR}$ at pH 7, 3 and after adsorption, (b) Pseudo-second order kinetic model, (c) Langmuir isotherm of CR, (d) $\mathrm{MO}$ dye removal efficiency with time (inset: optical image of $\mathrm{MO}$ before and after adsorption), (e) Pseudo second-order for $\mathrm{MO}$, (f) Langmuir isotherm for $\mathrm{MO}$, (g) $\mathrm{AB}$ dye removal efficiency with time (inset: optical image of AB before and after adsorption), (h) Pseudo-second order kinetics, (i) Langmuir isotherm for AB.
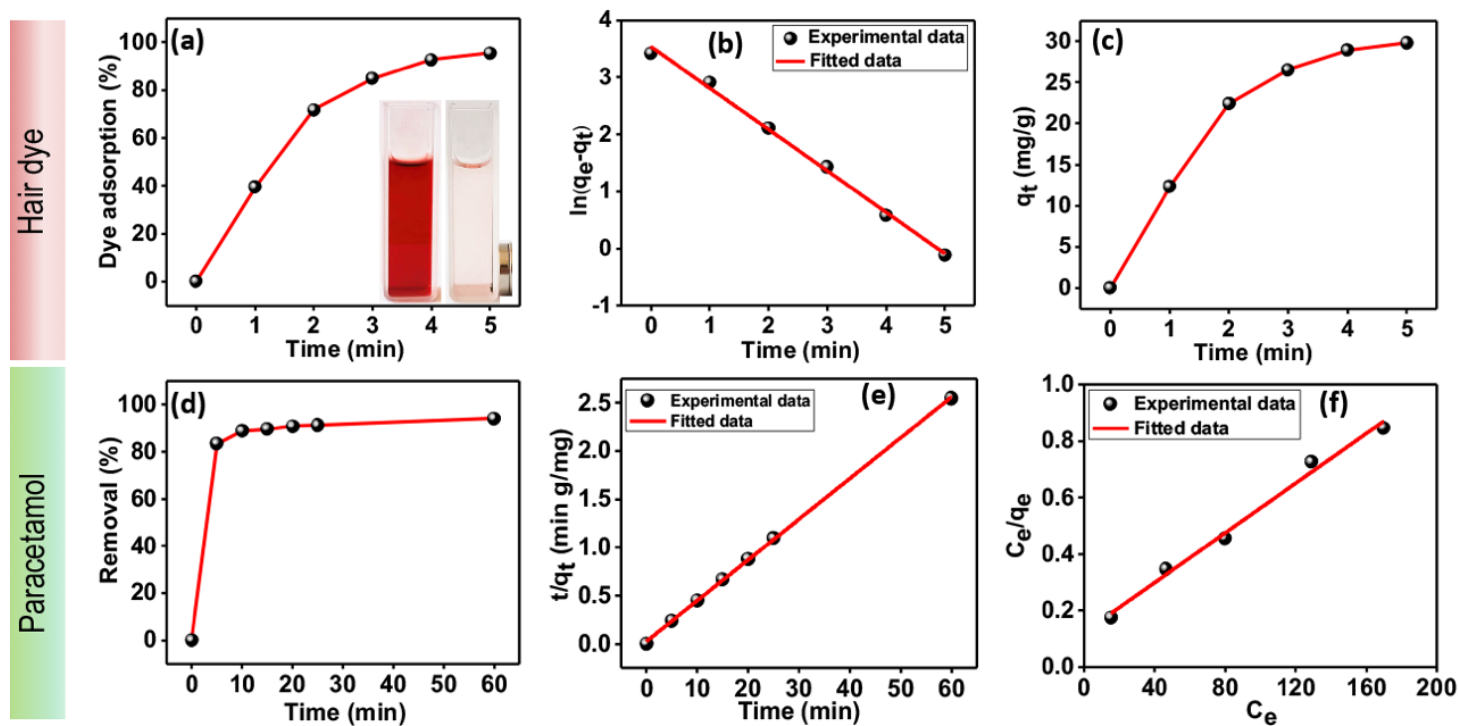

Figure 7: (a) Removal efficiency of hair dye with time (inset: hair dye before and after adsorption), (b) Pseudo-first order kinetics, (c) effect of contact time with adsorption capacity, (d) Removal efficiency of paracetamol with time, (e) Pseudo-second order kinetics, (f) Langmuir isotherm model for paracetamol. 


\subsection{Adsorption and regeneration studies}

Reusability of the adsorbent material is very much important for economic and environmental benefit. At first, after the adsorption of dye, adsorbent (CFC-1) was recovered using an external magnet. The collected adsorbent was treated with ethanol and sonicated for $1 \mathrm{~h}$ followed by $1 \mathrm{hr}$ stirring. After the desorption process, the adsorbent was dried at $200^{\circ} \mathrm{C}$ for $6 \mathrm{hr}$ in order to remove all the moisture content. This process of adsorption and desorption is carried out for five consecutive cycles at optimal $\mathrm{pH}$ of each dye/paracetamol and the dye/paracetamol removal efficiency is calculated for each cycle using UV-Vis absorption spectrophotometry. As the adsorption was reversible, the regeneration process was favorable. It was seen that even in the fifth cycle, reused CFC-1 could adsorb 83$89 \%$ dye and $\sim 68 \%$ of paracetamol (figure 8 ).

To confirm that adsorption over CFC-1 doesn't lead to any chemical changes to the dyes which will confirm the reusability of the recovered dye. The recovered dyes were characterized by UV-Vis spectrophotometry in ethanol solution using $10 \mathrm{~mm}$ quartz cuvette. The almost same absorption maximum values in UV-Vis absorption spectra of the recovered dyes confirm that no chemical change/degradation happens to the dye molecules (Figure S10-S12). The adsorption and regeneration studies suggest that the CFC-1 composite shows high efficiency, reusability and recovery of the adsorbed dye/paracetamol and thus confirms its real time applicability.

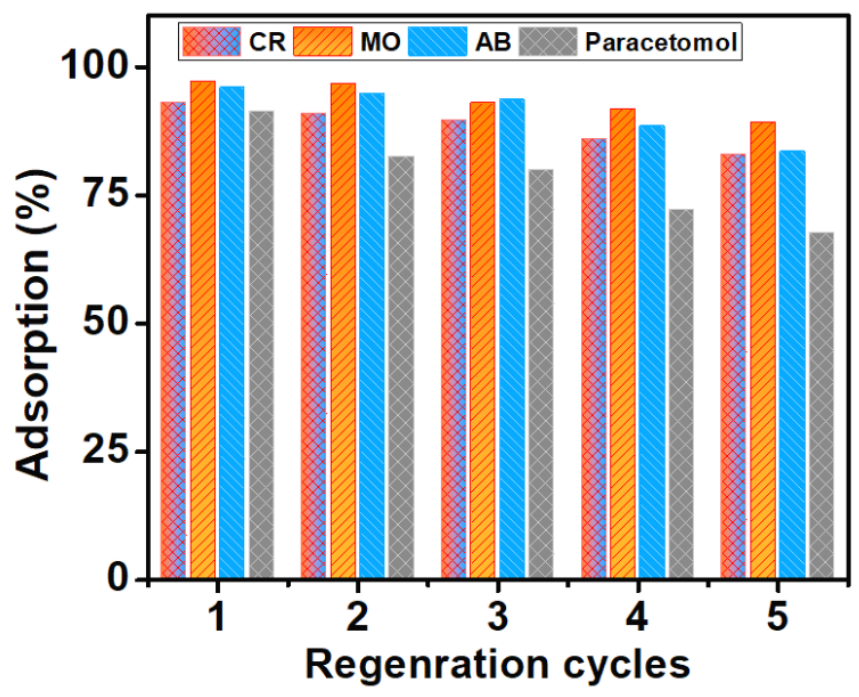

Figure 8: Adsorption of dyes/paracetamol over CFC-1 in different regeneration cycles.

\section{Conclusions}

In conclusions, the cobalt-iron alloyed partially graphitized carbon composite (CFC-1) with synergistic properties for the removal of organic anionic dyes, hair dye and pharmaceutical drug; has been synthesized successfully. The CFC-1 exhibited high magnetic property compared to the reported values of magnetic adsorbent. The fast and higher adsorption of dyes/paracetamol over CFC-1 as compared to its control samples CFC-0, CC, CF suggest the role of synergetic effect of cobalt-iron alloy. The kinetic and isotherm study of adsorption were using different models. The faster and higher adsorption, easy recovery of the adsorbed dyes/paracetamol, reusability and no structural changes in the adsorbate molecules suggest that the developed magnetic adsorbent is a potential candidate of real time application for large scale study.

\section{Conflicts of interest}

Authors have no conflicts to declare.

\section{Acknowledgements}

S.R.M. acknowledges Jain University for Junior Research fellowship. M.S. is grateful to the SERB, New Delhi, India for funding to conduct the research (EMR/2017/003368). The authors acknowledge the NANOMISSION project (SR/NM/ NS20/2014) for FESEM and PXRD facility. The authors acknowledge the TEM Facility, funded by a TPF Nanomission, Gol project at Centre for Nano and Soft Matter Sciences, Bengaluru. Authors also thank to Indian Institute of Technology Kanpur, India for VSM characterization. S.R.M. and M.S. thanks to Prof. S. K. Nataraj, CNMS, Jain University to allow furnace use for the present research.

\section{Notes and references}

¥Footnotes relating to the main text should appear here. These might include comments relevant to but not central to the matter under discussion, limited experimental and spectral data, and crystallographic data.

(1) Shen, X.; Ma, S.; Xia, H.; Shi, Z.; Mu, Y.; Liu, X. Cationic porous organic polymers as an excellent platform for highly efficient removal of pollutants from water. J. Mater. Chem. A 2018, 6, 20653-20658.

(2) Gadipelly, C.; Pérez-González, A.; Yadav, G. D.; Ortiz, I.; Ibáñez, R.; Rathod, V. K.; Marathe, K. V. Pharmaceutical Industry Wastewater: Review of the Technologies for Water Treatment and Reuse. Ind. Eng. Chem. Res. 2014, 53, 11571-11592.

(3) Manohara, H. M.; Aruchamy, K.; Chakraborty, S.; Radha, N.; Nidhi, M. R.; Ghosh, D.; Nataraj, S. K.; Mondal, D. Sustainable Water Purification Using an Engineered Solvothermal Carbon Based Membrane Derived from a Eutectic System. ACS Sustain Chem Eng 2019, 7, 10143-10153.

(4) Anliker, R. Ecotoxicology of dyestuffs-A joint effort by industry. Ecotoxicology and Environmental Safety 1979, 3, 59-74.

(5) Chowdhury, A.; Khan, A. A.; Kumari, S.; Hussain, S. Superadsorbent $\mathrm{Ni}-\mathrm{Co}-\mathrm{S} / \mathrm{SDS}$ Nanocomposites for Ultrahigh Removal of Cationic, Anionic Organic Dyes and Toxic Metal Ions: Kinetics, Isotherm and Adsorption Mechanism. ACS Sustain Chem Eng 2019, 7, 4165-4176.

(6) Liu, R.; Fu, H.; Yin, H.; Wang, P.; Lu, L.; Tao, Y. A facile sol combustion and calcination process for the preparation of magnetic $\mathrm{NiO} .5 \mathrm{Zn} 0.5 \mathrm{Fe} 2 \mathrm{O} 4$ nanopowders and their adsorption behaviors of Congo red. Powder Technol. 2015, 274, 418-425. 
(7) Bhowmik, M.; Deb, K.; Debnath, A.; Saha, B. Mixed phase Fe2O3/Mn3O4 magnetic nanocomposite for enhanced adsorption of methyl orange dye: Neural network modeling and response surface methodology optimization. Appl. Organomet. Chem. 2018, 32, e4186.

(8) Kim, S.-H.; Choi, P.-P. Enhanced Congo red dye removal from aqueous solutions using iron nanoparticles: adsorption, kinetics, and equilibrium studies. Dalton Transactions 2017, 46, 15470-15479.

(9) Chatterjee, S.; Tran, H. N.; Godfred, O.-B.; Woo, S. H. Supersorption Capacity of Anionic Dye by Newer Chitosan Hydrogel Capsules via Green Surfactant Exchange Method. ACS Sustainable Chemistry \& Engineering 2018, 6, 3604-3614.

(10) Raval, N. P.; Shah, P. U.; Shah, N. K. Adsorptive amputation of hazardous azo dye Congo red from wastewater: a critical review. Environmental Science and Pollution Research 2016, 23, 1481014853.

(11) Gong, R.; Ye, J.; Dai, W.; Yan, X.; Hu, J.; Hu, X.; Li, S.; Huang, H. Adsorptive Removal of Methyl Orange and Methylene Blue from Aqueous Solution with Finger-Citron-Residue-Based Activated Carbon. Industrial \& Engineering Chemistry Research 2013, 52, 14297-14303.

(12) Morel, O. J. X.; Christie, R. M. Current Trends in the Chemistry of Permanent Hair Dyeing. Chemical Reviews 2011, 111, 2537-2561.

(13) Hair dyes focus of latest cancer scare. Chemical \& Engineering News Archive 1975, 53, 8.

(14) Zhang, Y.; Kim, C.; Zheng, T. Hair dye use and risk of human cancer. Front Biosci (Elite Ed) 2012, 4, 516-528.

(15) Towle, K. M.; Grespin, M. E.; Monnot, A. D. Personal use of hair dyes and risk of leukemia: a systematic literature review and metaanalysis. Cancer Medicine 2017, 6, 2471-2486.

(16) Ruiz, B.; Cabrita, I.; Mestre, A. S.; Parra, J. B.; Pires, J.; Carvalho, A. P.; Ania, C. O. Surface heterogeneity effects of activated carbons on the kinetics of paracetamol removal from aqueous solution. Appl. Surf. Sci. 2010, 256, 5171-5175.

(17) Trujillo, C.; Gago, C.; Ramos, S. Stevens-Jonhson syndrome after acetaminophen ingestion, confirmed by challenge test in an elevenyear-old patient. Allergologia et Immunopathologia 2010, 38, 99100.

(18) Biswal, S.; Sahoo, S. S. Paracetamol induced Stevens-Johnson syndrome - toxic epidermal necrolysis overlap syndrome. International Journal of Dermatology 2014, 53, 1042-1044.

(19) Rakić, V.; Rajić, N.; Daković, A.; Auroux, A. The adsorption of salicylic acid, acetylsalicylic acid and atenolol from aqueous solutions onto natural zeolites and clays: Clinoptilolite, bentonite and kaolin. Microporous Mesoporous Mater. 2013, 166, 185-194.

(20) Bao, Z.; Ye, L.; Fang, B.; Zhao, L. Synthesis of Fe0.32Co0.68/YAl2O3@C nanocomposite for depth treatment of dye sewage based on adsorption and advanced catalytic oxidation. J. Mater. Chem. A 2017, 5, 6664-6676.

(21) Moosavi, S.; Lai, C. W.; Gan, S.; Zamiri, G.; Akbarzadeh Pivehzhani, O.; Johan, M. R. Application of Efficient Magnetic Particles and Activated Carbon for Dye Removal from Wastewater. ACS Omega 2020, 5, 20684-20697.

(22) Chatterjee, S.; Guha, N.; Krishnan, S.; Singh, A. K.; Mathur, P.; Rai, D. K. Selective and Recyclable Congo Red Dye Adsorption by Spherical Fe3O4 Nanoparticles Functionalized with 1,2,4,5Benzenetetracarboxylic Acid. Scientific Reports 2020, 10, 111.

(23) Far, H. S.; Hasanzadeh, M.; Nashtaei, M. S.; Rabbani, M.; Haji, A.; Hadavi Moghadam, B. PPI-Dendrimer-Functionalized Magnetic Metal-Organic Framework (Fe304@MOF@PPI) with High Adsorption Capacity for Sustainable Wastewater Treatment. ACS Appl. Mater. Interfaces 2020, 12, 25294-25303.
(24) Mou, Y.; Yang, H.; Xu, Z. Morphology, Surface Layer Evolution, and Structure-Dye Adsorption Relationship of Porous Fe304 MNPs Prepared by Solvothermal/Gas Generation Process. ACS Sustain Chem Eng 2017, 5, 2339-2349.

(25) Han, L.-J.; Ge, F.-Y.; Sun, G.-H.; Gao, X.-J.; Zheng, H.-G. Effective adsorption of Congo red by a MOF-based magnetic material. Dalton Transactions 2019, 48, 4650-4656.

(26) Sarkar, A. K.; Bediako, J. K.; Choi, J.-W.; Yun, Y.-S. Functionalized magnetic biopolymeric graphene oxide with outstanding performance in water purification. NPG Asia Materials 2019, 11, 4.

(27) Guo, M.; Song, M.; Li, S.; Yin, Z.; Song, X.; Bu, Y. Facile and economical synthesis of $\mathrm{ZnS}$ nanotubes and their superior adsorption performance for organic dyes. CrystEngComm 2017, 19, 2380-2393. (28) Zheng, Y.; Zhu, B.; Chen, H.; You, W.; Jiang, C.; Yu, J. Hierarchical flower-like nickel(II) oxide microspheres with high adsorption capacity of Congo red in water. J. Colloid Interface Sci. 2017, 504, 688-696.

(29) Li, H.; Cao, X.; Zhang, C.; Yu, Q.; Zhao, Z.; Niu, X.; Sun, X.; Liu, Y.; $\mathrm{Ma}$, L.; Li, Z. Enhanced adsorptive removal of anionic and cationic dyes from single or mixed dye solutions using MOF PCN-222. RSC Advances 2017, 7, 16273-16281.

(30) Li, X.; Lu, X.; Yang, J.; Ju, Z.; Kang, Y.; Xu, J.; Zhang, S. A facile ionic liquid approach to prepare cellulose-rich aerogels directly from corn stalks. Green Chemistry 2019,

(31) Mohanta, J.; Dey, B.; Dey, S. Magnetic Cobalt Oxide Nanoparticles: Sucrose-Assisted Self-Sustained Combustion Synthesis, Characterization, and Efficient Removal of Malachite Green from Water. J. Chem. Eng. Data 2020, 65, 2819-2829.

(32) Hara, Y.; Kanamori, K.; Morisato, K.; Miyamoto, R.; Nakanishi, K. Iron(iii) oxyhydroxide and oxide monoliths with controlled multiscale porosity: synthesis and their adsorption performance. J. Mater. Chem. A 2018, 6, 9041-9048.

(33) del Rio, M.; Turnes Palomino, G.; Palomino Cabello, C. MetalOrganic Framework@Carbon Hybrid Magnetic Material as an Efficient Adsorbent for Pollutant Extraction. ACS Appl. Mater. Interfaces 2020, 12, 6419-6425.

(34) Manippady, S. R.; Singh, A.; Basavaraja, B. M.; Samal, A. K.; Srivastava, S.; Saxena, M. Iron-Carbon Hybrid Magnetic Nanosheets for Adsorption-Removal of Organic Dyes and 4-Nitrophenol from Aqueous Solution. ACS Applied Nano Materials 2020, 3, 1571-1582.

(35) Soliman, E. M.; Ahmed, S. A.; Fadl, A. A. Reactivity of sugar cane bagasse as a natural solid phase extractor for selective removal of $\mathrm{Fe}(\mathrm{III})$ and heavy-metal ions from natural water samples. Arabian Journal of Chemistry 2011, 4, 63-70.

(36) Manippady, S. R.; Singh, A.; Rout, C. S.; Samal, A. K.; Saxena, M. Partially Graphitized Iron-Carbon Hybrid Composite as an Electrochemical Supercapacitor Material. ChemElectroChem 2020, 7, 1928-1934.

(37) Cheng, Y.; Ji, G.; Li, Z.; Lv, H.; Liu, W.; Zhao, Y.; Cao, J.; Du, Y. Facile synthesis of FeCo alloys with excellent microwave absorption in the whole Ku-band: Effect of Fe/Co atomic ratio. J. Alloys Compd. 2017, 704, 289-295.

(38) Wu, A.; Yang, X.; Yang, H. Magnetic properties of carbonencapsulated Fe-Co alloy nanoparticles. Dalton Trans 2013, 42, 4978-4984.

(39) Sevilla, M.; Fuertes, A. B. Catalytic graphitization of templated mesoporous carbons. Carbon 2006, 44, 468-474.

(40) Moghaddam, A. Z.; Jazi, M. E.; Allahrasani, A.; Ganjali, M. R.; Badiei, A. Removal of acid dyes from aqueous solutions using a new eco-friendly nanocomposite of $\mathrm{CoFe} 2 \mathrm{O} 4$ modified with Tragacanth gum. J. Appl. Polym. Sci. 2020, 137, 48605. 
(41) Wang, Z.; Jiang, Y.; Li, Y.; Huo, H.; Zhao, T.; Li, D.; Lin, K.; Xu, X. Synthesis of Porous Fe3C-Based Composite Beads as Heterogeneous Oxidation Catalysts. Chemistry - A European Journal 2019, 25, 41754183.

(42) Dai, J.; Tian, S.; Jiang, Y.; Chang, Z.; Xie, A.; Zhang, R.; Li, C.; Yan, $\mathrm{Y}$. $\mathrm{Fe} 3 \mathrm{C} / \mathrm{Fe} / \mathrm{C}$ Magnetic Hierarchical Porous Carbon with Micromesopores for Highly Efficient Chloramphenicol Adsorption: Magnetization, Graphitization, and Adsorption Properties Investigation. Ind. Eng. Chem. Res. 2018, 57, 3510-3522.

(43) Aboelfetoh, E. F.; Elhelaly, A. A.; Gemeay, A. H. Synergistic effect of $\mathrm{Cu}(\mathrm{II})$ in the one-pot synthesis of reduced graphene oxide ( $\mathrm{rGO} / \mathrm{CuxO}$ ) nanohybrids as adsorbents for cationic and anionic dyes. Journal of Environmental Chemical Engineering 2018, 6, 623-634.

(44) Ranjithkumar, V.; Sangeetha, S.; Vairam, S. Synthesis of magnetic activated carbon/ $\alpha-\mathrm{Fe} 2 \mathrm{O} 3$ nanocomposite and its application in the removal of acid yellow 17 dye from water. J. Hazard. Mater. 2014, 273, 127-135.

(45) Cazetta, A. L.; Pezoti, O.; Bedin, K. C.; Silva, T. L.; Paesano Junior, A.; Asefa, T.; Almeida, V. C. Magnetic Activated Carbon Derived from Biomass Waste by Concurrent Synthesis: Efficient Adsorbent for Toxic Dyes. ACS Sustainable Chemistry \& Engineering 2016, 4, 10581068.

(46) Zhou, L.; Shao, Y.; Liu, J.; Ye, Z.; Zhang, H.; Ma, J.; Jia, Y.; Gao, W.; $\mathrm{Li}, \mathrm{Y}$. Preparation and Characterization of Magnetic Porous Carbon Microspheres for Removal of Methylene Blue by a Heterogeneous Fenton Reaction. ACS Appl. Mater. Interfaces 2014, 6, 7275-7285.

(47) Zan, F. L.; Ma, Y. Q.; Ma, Q.; Zheng, G. H.; Dai, Z. X.; Wu, M. Z.; Li, G.; Sun, Z. Q.; Chen, X. S. One-step hydrothermal synthesis and characterization of high magnetization CoFe2O4/Co0.7Fe0.3 nanocomposite permanent magnets. J. Alloys Compd. 2013, 553, 7985.

(48) Casula, M. F.; Concas, G.; Congiu, F.; Corrias, A.; Falqui, A.; Spano, G. Near Equiatomic FeCo Nanocrystalline Alloy Embedded in an Alumina Aerogel Matrix: Microstructural Features and Related Magnetic Properties. The Journal of Physical Chemistry B 2005, 109, 23888-23895.

(49) Spessato, L.; Bedin, K. C.; Cazetta, A. L.; Souza, I. P. A. F.; Duarte, V. A.; Crespo, L. H. S.; Silva, M. C.; Pontes, R. M.; Almeida, V. C. KOHsuper activated carbon from biomass waste: Insights into the paracetamol adsorption mechanism and thermal regeneration cycles. J. Hazard. Mater. 2019, 371, 499-505.

(50) Elhaddaoui, A.; Merlin, J. C.; Delacourte, A.; Turrell, S. Spectroscopic studies of the effect of $\mathrm{pH}$ on the interaction between congo red and amyloid-type proteins. J. Mol. Struct. 1992, 267, 113116.

(51) Lei, C.; Zhu, X.; Le, Y.; Zhu, B.; Yu, J.; Ho, W. Hierarchically porous $\mathrm{NiO}-\mathrm{Al} 2 \mathrm{O} 3$ nanocomposite with enhanced Congo red adsorption in water. RSC Adv. 2016, 6, 10272-10279.

(52) Dhanavel, S.; Nivethaa, E. A. K.; Dhanapal, K.; Gupta, V. K.; Narayanan, V.; Stephen, A. $\alpha-\mathrm{MoO} 3 /$ polyaniline composite for effective scavenging of Rhodamine $B$, Congo red and textile dye effluent. RSC Adv. 2016, 6, 28871-28886.

(53) Sharma, P.; Hussain, N.; Borah, D. J.; Das, M. R. Kinetics and Adsorption Behavior of the Methyl Blue at the Graphene Oxide/Reduced Graphene Oxide Nanosheet-Water Interface: A Comparative Study. Journal of Chemical \& Engineering Data 2013, 58, 3477-3488.

(54) Lladó, J.; Lao-Luque, C.; Ruiz, B.; Fuente, E.; Solé-Sardans, M.; Dorado, A. D. Role of activated carbon properties in atrazine and paracetamol adsorption equilibrium and kinetics. Process Safety and Environmental Protection 2015, 95, 51-59. 